\title{
CONCEPÇÕES DE CASAMENTO EM REVISTAS FEMININAS BRASILEIRAS DO SÉCULO XIX ${ }^{1}$
}

\section{MARRIAGE CONCEPTION BY FEMALE MAGAZINES IN THE NINETEENTH CENTURY}

Elisa Maria Verona ${ }^{2}$

\section{RESUMO}

O casamento foi tema amplamente discutido pela elite letrada brasileira dos oitocentos. Juristas, médicos, literatos e demais escritores mostraram-se fortemente comprometidos com a noção de que a promoção de casamentos legítimos era uma garantia segura de ordem e moralidade para a sociedade. O propósito desse estudo é analisar as concepções de casamento defendidas pelos periódicos brasileiros direcionados ao público feminino, abordando, entre outras questões, o problema dos matrimônios arranjados e dos deveres que marido e esposa deviam cumprir para o bom convívio conjugal.

Palavras-chave: Casamento; imprensa feminina; século XIX.

\begin{abstract}
Marriage was a subject massively discussed by the Brazilian literate elite in the nineteenth century. Lawyers, doctors, literates, and other writers were strongly committed to the idea that legitimate marriages were a safe guarantee of order and morality to the society. The purpose of this study is to analyze marriage conceptions defended by Brazilian periodicals to the female audience, approaching the arranged marriage issue and the duties that husbands and wives should fulfill for the good marital cohabitation.
\end{abstract}

Key words: Marriage; women's press; nineteenth century.

\section{Introdução}

Durante o século XIX, a imprensa periódica brasileira, em especial o segmento de revistas direcionadas ao público feminino, desenvolveu-se consideravelmente. O fim do monopólio da Impressão Régia, o aumento do número de livreiros, sobretudo na corte, e o surgimento de diversos periódicos e associações comprometidos com a difusão do saber favoreceram imensamente o debate de opiniões e a formação de um público receptor para os

\footnotetext{
1 Essa pesquisa contou com o apoio financeiro CAPES.

2 Doutora em História pela UNESP, Campus Franca. E-mail: elisa.verona@bol.com.br
}

Divers@Revista Eletrônica Interdisciplinar/Matinhos/Vol.5, n.1/p.1-92|/jan./jun.2012 
conteúdos impressos. A partir de 1820, a consciência da formação de um público leitor feminino manifesta-se pela publicação de diversos periódicos destinados a esse público. $\mathrm{O}$ pioneirismo no setor foi do $O$ espelho diamantino, publicado a partir de 1827 no Rio de Janeiro, posteriormente seguido de $O$ mentor das brasileiras, publicado de 1829 a $1832 \mathrm{em}$ São João Del Rei, $O$ espelho das brasileiras, publicado em Recife a partir de 1831, e o $A$ mulher de Simplício ou a fluminense exaltada, editado na corte pelo famoso livreiro Paula Brito, a partir de 1832. Depois dessas primeiras experiências, o setor não parou mais de crescer. Em 1852, é a vez de as próprias mulheres tomarem a frente da direção de periódicos de interesse feminino. A iniciativa coube a Joana Paula Manso de Noronha, responsável pela fundação do Jornal das senhoras. Posteriormente, outras brasileiras também tiveram a iniciativa de instituir novos periódicos, todas motivadas pela intenção de promover a educação feminina e deleitar o "belo sexo" nas suas horas de descanso.

Em geral, esses periódicos dirigidos à mulher guardavam uma estrutura semelhante: praticamente todos dedicavam seções às novelas, aos versos, à moda, à economia doméstica e aos conselhos morais. A preocupação instrutiva e moralizadora também era um traço marcante nessas publicações. O casamento, ao lado da preocupação com a instrução feminina, foi um tema de grande relevância - é bem variada a quantidade de artigos que abordam a questão dos matrimônios, apresentando, no geral, uma preocupação instrutiva ou informativa apoiada em argumento médico, religioso, moral ou mesmo na tradição. São artigos que também contrariam, em grande medida, algumas práticas frequentes na população brasileira do século XIX, como a dos casamentos em idade precoce, dos casamentos arranjados, entre outros. Uma passada de olhos pelos títulos de alguns artigos ajuda a demonstrar quão grande foi a abrangência de aspectos explorados: Instrução para moças que vão casar, Conselhos as desposadas, Conselhos de um pai a sua filha na véspera do seu noivado, Conselhos as esposas zelosas, Qualidades de uma esposa perfeita e como deve ser ela tratada. Mas antes de tratarmos dos modelos de comportamento sugeridos às esposas, vejamos como o casamento é definido por esses periódicos.

No periódico $A$ violeta fluminense, revista quinzenal dedicada aos interesses do belo sexo, o casamento é definido, em artigo de17 de janeiro de 1858, como laço sagrado e indissolúvel que constitui um dos sacramentos da religião católica. $O$ sexo feminino, dirigido

Divers@Revista Eletrônica Interdisciplinar/Matinhos/Vol.5, n.1/p.1-92|/jan./jun.2012 
por Francisca Senhorinha da Motta Diniz ${ }^{3}$ e publicado semanalmente na corte, também define o casamento como obra de Deus, com grande finalidade social - "casar é adquirir a santa liberdade do espírito e sacudir a tirania das paixões". O casamento é considerado a base da sociedade, um meio de legitimar perante a sociedade a união entre os sexos, afirma a redatora da revista em artigo que data de 29 de julho de 1875, no qual ainda acrescenta que quanto maior for o número de casados, menor será o número de criminosos. Em outro artigo, de 18 de agosto de 1874, intitulado $O$ amor conjugal, D. Francisca S. da M. Diniz lembra a suas leitoras que a união pelo laço do matrimônio não se trata de simples contrato, mas sim de um contrato abençoado que não deve ser desfeito. Artigo publicado no Jornal das senhoras, de 11 de abril de 1852, intitulado Palavras de um pároco a uma noiva, aborda essa diferença com bastante precisão - vejamos o argumento do padre quanto às diferenças entre casamento cristão e casamento baseado na filosofia:

\begin{abstract}
Muito em breve, minha filha, ides deixar o véu de virgem, o teto paterno e as descuidosas ocupações de vossa mocidade, pelas ocupações muito mais sérias e muito mais importantes de esposa e mãe de família. O casamento! A filosofia e a religião concebem esse ato da vida social de uma maneira bem diferente. O filosofo vos dirá: o casamento é o complemento e a realização das afeições de dois corações que se dedicam um para o outro, para se fazerem mutuamente felizes nessa vida. $\mathrm{O}$ cristianismo vos dirá alguma coisa a mais do que isso: ele vos ensinará que ides celebrar na terra um contrato que se sanciona no céu (...), ele vos dirá que esse ato é santo, é sublime, é celeste. Acreditai-me, minha filha, se Deus não intervir nesse negócio, se o amor conjugal for só filosófico e não cristão, então a base dessa união é bem fraca, bem movediça, bem precária. ${ }^{4}$
\end{abstract}

Definido como sacramento religioso, o casamento não deve ser confundido com contrato civil, conforme defende o redator de $O$ cherubim $^{5}$, em artigo publicado em três números do periódico, de 12, 19, 26 de dezembro de 1886. Com o propósito de prestar um importante serviço a família e a sociedade, o redator apresenta uma comparação entre as duas formas de casamento e chama suas leitoras a reagirem contra a união civil, tida como uma espécie de imoralidade autorizada. O casamento civil, de acordo com esse ensaio, degrada a mulher e a torna desprezível aos olhos da sociedade - só através do matrimônio cristão é que

3 Professora, jornalista e escritora natural de São João Del Rei, Francisca Senhorinha da Motta Diniz fundou, em 1873, na cidade de Campanha da Princesa, o periódico O sexo feminino, que algum tempo depois passou a ser publicado no Rio de Janeiro. Artigos sobre a educação feminina e a emancipação da mulher eram abundantes nesse periódico. Além deles, os romances e as poesias também eram presença frequente.

4 JORNAL DAS SENHORAS: modas, literatura, belas artes, teatros e criticas. Rio de Janeiro: Tipografia Parisiense 10/04/1852.

5 Periódico semanal publicado no Rio de Janeiro entre os anos 1885 e 1887. O proprietário do periódico se identifica pelas iniciais J. A. M. O ensaio mencionado não é assinado e deve ter sido escrito pelos redatores do periódico, que se definem como moços que querem proporcionar momentos de distração a suas leitoras.

Divers@Revista Eletrônica Interdisciplinar/Matinhos/Vol.5,n.1/p.1-92//jan./jun.2012 
se pode garantir a sua honra e seu futuro. $\mathrm{O}$ que o autor tem em mente quando repudia o casamento civil é a possibilidade de divórcio que ele inevitavelmente abriga, conforme expõem no seguinte trecho:

O matrimônio civil não degrada somente a mulher, vai além: mina a constituição da família, cobrindo esta de luto, de vergonha e de todas as misérias. A família, que tem por base o matrimonio religioso, no qual vê a garantia de futuro dos filhos e da honestidade de suas filhas, ver-se-a exposta aos caprichos de todas as paixões e ao perigo de ver sua filha, depois de casada civilmente, voltar para casa se não quiser expor-se às misérias de seu sexo, infamada, repudiada, coberta de vergonha, em consequência de um divórcio. ${ }^{6}$

O apelo da revista não é divulgado despropositadamente, visto que ao longo do século XIX discutiu-se sobre a necessidade de secularizar o casamento. Projetos de lei favoráveis ao casamento civil tramitaram na câmara dos deputados pelo menos desde 1856 e tinham como preocupação fundamental a situação legal dos indivíduos não católicos. Apesar dos inúmeros debates, a lei canônica sobre os casamentos prevaleceu até a instauração da República, quando finalmente foi decretada a secularização do matrimônio.

Talvez mais preocupante que a questão do casamento civil era a frequência dos casamentos ilegítimos entre a população. No jornal Marmota fluminense, de 7 de maio de 1858, encontramos um artigo que aborda justamente esse problema. $\mathrm{O}$ autor, que assina pela letra R., reclama da indiferença das leis e da opinião pública e fala dos onerosos encargos para os consórcios. Recorda um tempo em que os solteiros não conseguiam emprego com tanta facilidade e conclui que os homens devem viver para a sociedade e esta exige que eles se casem.

A realização dos casamentos favorece até mesmo a longevidade, defende o artigo Efeitos do casamento sobre a duração da vida, publicado no Jornal das senhoras, de 6 de março de 1853. Apresentando os estudos de doutor Casper, publicado em Berlim, o artigo propõem que os celibatários vivem menos que os casados e que há maior número de suicídios entre os solteiros. "É fato incontestavelmente estabelecido que nos dois sexos o casamento é favorável ao aumento da vida", afirma a autora do ensaio. Em Segredos da longevidade, ensaio publicado no periódico $O$ sexo feminino, de 7 de novembro de 1875 , a conclusão é a mesma que a do artigo anterior: "O casamento é uma das coisas que contribui para a duração da vida, por isso é que vemos poucos solteiros chegarem a uma idade avançada.”

6 O CHERUBIM: dedicado ao belo sexo. Rio de Janeiro: Tipografia Montenegro. 12/12/1886.

Divers@ Revista Eletrônica Interdisciplinar/Matinhos/Vol.5, n.1/p.1-92//jan./jun.2012 
O celibato, artigo de Dr. L. Seraine para o periódico $A$ mãe de família ${ }^{7}$, de junho de 1881, também menciona os estudos de Dr. Casper que tratam da maior duração da vida para pessoas casadas. O celibato é contrário a nossa natureza e se fosse praticado em grande escala seria um atentado contra a conservação da espécie, afirma Dr. L. Seraine. Ele torna a mulher mais suscetível a doenças e arrasta os homens às tabernas e lugares suspeitos, além de levá-lo a pensar em ideias suicidas e homicidas e afastá-lo da religião - "Nunca um celibatário passou de cem anos".

Mas esses periódicos não se preocuparam apenas em definir o casamento e descrever suas incontáveis vantagens. Ocuparam-se, sobretudo, de divulgar uma quantidade considerável de textos normativos que traziam alguns conselhos para o sucesso matrimonial, delimitavam o papel social do homem e da mulher no casamento e estabeleciam os modelos aceitáveis de união.

Sobre a questão dos casamentos precoces, o Jornal das senhoras publica em 23 de agosto de 1852 uma carta de B. Franklin a John Alleyne na qual o autor escreve que a idade juvenil do homem e da mulher não deve ser considerada um impedimento para a realização do matrimônio. As pessoas de pouca idade, por possuírem um caráter mais flexível, acostumamse mais facilmente uns com os outros e o casamento contribui para habituar os moços a uma vida regular, além de evitar relações nocivas à saúde e à reputação, observa Franklin. No caso em que os jovens demonstrarem falta de prudência, os parentes mais maduros podem intervir com conselhos que supra a falta de experiência dos mais novos.

O argumento de Dr. Carlos Costa contraria a ideia de que se deve contrair casamento logo que a natureza torne a pessoa fisicamente apta ao matrimônio. Conforme expõe em artigo de janeiro 1881 para $A$ mãe de família, a menina nos seus 13 anos ainda não completou o desenvolvimento dos órgãos próprios para a reprodução, como também não podem compreender os elevados e difíceis encargos da maternidade. O médico mostra-se contrário ao casamento antes dos 18 anos e defende que essa e outras situações indesejáveis poderiam ser evitadas se o médico de família fosse ouvido - a intervenção do médico na grave questão do casamento não deve ignorada.

Periódico quinzenal fundado em 1879, no Rio de Janeiro, pelo médico Carlos Costa, especialista em moléstias infantis. A principal intenção da folha era a de preencher uma importante lacuna na educação da mulher, ou seja, desejava instruir as mães de família, ensinar como se cuida de uma criança e demonstrar que a educação da primeira infância compete à mãe.

Divers@Revista Eletrônica Interdisciplinar/Matinhos/ Vol.5,n.1/p.1-92//jan./jun.2012 
Artigo publicado no periódico $O$ sexo feminino, de 12 de setembro de 1875, conclui, baseado em "laboriosa investigação, comprovada por numerosas estatísticas", que é entre os 18 e os 23 anos que a mulher encontra maiores chances de se casar - a probabilidade de contrair matrimônio diminui conforme a idade da mulher aumenta.

Se quanto à idade ideal para contrair matrimônio houve divergência de opiniões, o mesmo não se fez notar quando o assunto é casamentos forçados ${ }^{8}$. Continuando com os conselhos médicos quanto aos matrimônios, o doutor Champfleury argumenta que para se gerar bons filhos devíamos modificar profundamente as condições de realização dos casamentos. O médico defende que os casamentos deveriam ser determinados pelo amor, pela amizade e por simpatias comuns entre os esposos - interesse e conveniência deveriam ser palavras suprimidas dos dicionários - e critica as uniões baseadas exclusivamente no dinheiro, que contrariam o preceito divino: crescei e multiplicai-vos. Quando os pais têm aversão um pelo outro, produzem filhos infelizes, conclui o especialista nesse texto publicado em outubro de 1880, no periódico A mãe de família. Artigo de 25 de outubro de 1873, publicado em $O$ sexo feminino, também afirma que, sendo o fim do casamento na sociedade o de legitimar as uniões motivadas pelo amor, devemos repudiar o casamento contraído como forma de fazer fortuna, por caçadores de dote que não querem trabalhar.

A Marmota fluminense apresenta o tema da liberdade da mulher na escolha do marido. Em artigo de 16 de julho de 1852 o periódico defende que sem amor não pode haver confiança e que, pela ignorância de muitos pais, muitas mulheres fluminenses ainda têm casado obrigadas. Na edição de 30 de dezembro de 1852, outro artigo aborda a questão e chega mesmo a dizer que quando uma mulher é forçada a se casar com um homem a quem não ama, por obediência à vontade paterna, pode mesmo vir a tornar-se uma adúltera.

Em $A$ mensageira, revista literária dedicada à mulher brasileira, repete o ensinamento anterior. Em resposta a carta de uma de suas leitoras, publicada na edição de 28 de fevereiro

8 Mary Del Priore, na obra História do amor no Brasil, argumenta que em fins do século XIX pequenas mudanças se processaram quanto a presença do afeto e respeito entre os cônjuges. "Por forças de práticas sociais, uma certa ideia de casamento que fosse além do rasteiro negócio começa a circular". No entanto, acrescenta a historiadora, a velha dicotomia entre a mulher respeitável, condizente com o casamento e com a procriação, e a prostituta, com quem era permitido realizar as fantasias eróticas, ainda persistiria por um bom tempo. Muriel Nazzari, em outro interessante estudo que investiga o processo que levou ao desaparecimento da prática do dote, também afirma que, em fins do século XIX, o casamento ia deixando de ser encarado como arranjo de família ou como questão de bens para ganhar a conotação de vínculo pessoal entre indivíduos. A relativa diminuição da autoridade paterna, somada a um movimento tênue de emancipação dos filhos, sobretudo do filho homem, muito contribuiu para a definição de um novo código amoroso, defende a autora.

Divers@Revista Eletrônica Interdisciplinar/Matinhos/Vol.5,n.1/p.1-92//jan./jun.2012 
de 1898, a jornalista Maria Clara da Cunha Santos conclui que a felicidade do casamento depende do amor: "Disse-me que amava muito o seu noivo e que era por ele muito amada. Muito bem! O primeiro e mais forte alicerce está construído. O casamento sem amor ou o amor sem juízo são os melhores agentes das dissidências e dos divórcios."

Um último grupo de artigos que gostaríamos de tratar diz respeito aos conselhos dirigidos a moças em idade de se casar ou recém casadas. Esses artigos são numerosos e estão presentes em quase todos os periódicos consultados. Aparecem sob os mais variados títulos e têm o propósito comum de esclarecer sobre o papel social que a mulher deve desempenhar para a boa convivência conjugal.

No periódico $O$ Cherubim, de 25 de dezembro de 1885, encontramos um ensaio em forma de diálogo entre pai e filha em que o pai questiona se sua filha está certa da decisão de casar-se com seu pretendente. O pai também esclarece sobre as mudanças que se devem processar no decorrer da vida conjugal e diz a sua filha quais as atitudes deve tomar diante de algum aborrecimento do marido. "Quando acontece persuadir-se a mulher que o casamento estabelece igualdade de direitos, é inevitável a desordem da vida. A submissão é tão precisa à esposa como a filha". Outro artigo publicado nesse mesmo periódico, na edição de 14 de fevereiro de 1886, reproduz ponto de vista semelhante. Assinala que dentre as regras de conduta que a mulher casada deve observar para manter a paz doméstica, está a de não contradizer o marido e não se intrometer nos negócios. Só dar conselhos quando consultada, responder ao mau humor com afetuosidade, gostar do asseio e vestir-se com elegância e decência, fazer boa escolha das amigas e desconfiar das intrigas são outras dicas importantes para fazer da casa um lugar agradável ao marido, para que ele não procure os prazeres fora do lar, assegura a folha. No artigo escrito por Delminda Silveira para o periódico $A$ Mensageira ${ }^{9}$, de 15 de setembro de 1898 , lemos a seguinte descrição da mulher bem educada, que sabe se comportar como um verdadeiro anjo em seu lar:

Sim; para que sejais sempre amadas, é preciso que vossos maridos vos encontrem
sempre bem cuidadas, irrepreensíveis em vossas toilettes e penteado, sempre
amáveis e delicadas como quando os cativastes. (...) A mulher bem educada é
sempre amável e graciosa; sempre correta e sensata, sempre o bom anjo do lar.

9 Revista mensal dirigida por Presciliana Duarte de Almeida e publicada em São Paulo a partir de 1897. Crônicas, contos, poesias e novelas, além dos artigos sobre moral, eram sempre presença obrigatória em suas páginas. Colaboravam com esse periódico escritoras como Júlia Lopes de Almeida, Delminda Silveira, Adelina Lopes Vieira, Anália Emilia Franco, entre outras.

Divers@ Revista Eletrônica Interdisciplinar/Matinhos/Vol.5, n.1/p.1-92|/jan./jun.2012 
Deveis saber que o mais belo dote de uma dona de casa é o espírito de ordem; nisto se compreende o asseio, a economia, a boa direção dos negócios domésticos. ${ }^{10}$

Para o colaborador de $A$ violeta fluminense, de 31 de janeiro de 1858, o principal dever de uma donzela que deseja se casar é o de ser boa cristã e saber conduzir as atividades domésticas. Além disso, deve sempre conformar-se com a vontade do marido, amando-o e tratando sempre de agradá-lo, ainda que tenha alguns defeitos. Mesmo quando o marido mostrar-se intratável, a mulher deve, de acordo com os princípios da folha, tolerar com paciência o momento, já que não há coisa alguma que o tempo não abrande. "O casamento é pois o céu ou o inferno. Se a mulher conformar-se com a vontade do marido é o céu destes dois entes felizes, porém, se viverem em discórdia é o inferno, porque ambos andarão consumidos e alguma desgraça porá termo", conclui o autor do ensaio.

O sexo feminino, de 12 de novembro de 1875, publica alguns conselhos do bispo D. Antônio para o sucesso matrimonial. Dentre as obrigações da mulher casada, encontram-se os seguintes itens:

1. Amar seu marido;

2. Respeitá-lo como seu chefe;

3. Obedecer-lhe com afetuosa prontidão;

4. Adverti-lo com discrição e prudência;

5. Responder-lhe com toda a mansidão;

6. Servi-lo com desvelo;

7. Calar, quando o vir irritado;

8. Tolerar com paciência os seus desvelos. ${ }^{11}$

Nas obrigações do marido o bispo recomenda que ele ame e respeite sua esposa como sua companheira, dirigindo-a como the sendo sujeita e repreendendo-a com benignidade.

Um último exemplo de artigo preocupado em definir os papéis sociais de maridos e esposas é Esposo modelo, publicado em A família $^{12}$, de 13 de fevereiro de 1890. Para seu autor, mesmo a mulher de bons instintos, com bom senso e instrução, necessita ser guiada em

10 A MENSAGEIRA: Revista literária dedicada à mulher brasileira. Edição fac-similar. São Paulo: Imprensa Oficial do Estado, 1987. p. 362.

11 O SEXO FEMININO: semanário dedicado aos interesses da mulher. Rio de Janeiro. 12/11/ 1875.

12 Periódico fundado em São Paulo, em 1888, por Josefina Álvares de Azevedo. Transferido, passados alguns meses, para o Rio de Janeiro, A família á circularia, ininterruptamente, até 1897. A principal intenção da redatora desse periódico era promover a educação feminina e a emancipação da mulher. Em uma série de artigos publicados a partir de dezembro de 1889, Josefina A. Azevedo chega a defender, inclusive, o direito ao voto, ideia que também defenderia através do teatro, com a peça $O$ voto feminino, encenada nos palcos do Recreio Dramático em 26 de maio de 1890.

Divers@Revista Eletrônica Interdisciplinar/Matinhos/Vol.5,n.1/p.1-92//jan./jun.2012 
suas atitudes, e este papel é o bom marido que deve desempenhar. Vejamos como esses deveres são resumidos pelo periódico:

Um homem não pode ser bom marido se não foi feliz na escolha da mulher. Não deve ter em vista nem a fortuna, nem a beleza. Deve associar sua existência a uma mulher boa de coração, de gênio dócil, inteligente e simples, qualidades estas que dão em resultado a doce harmonia conjugal e as alegrias puras do lar. Aquele que melhor educa a mulher, eis o marido. (...) Longe de sofrer, nos primeiros passos da vida, da autoridade do marido, a jovem esposa, se for de boa índole e compreender seus deveres, julgar-se-á feliz em ser submissa aos conselhos sinceros daquele em quem ela deposita toda a sua confiança e amor. Aconselhar, censurar mesmo, mas com acerto em bondade, não é ser cruel, pelo contrário, é uma prova de estima. ${ }^{13}$

Em O álbum semanal, periódico literário e crítico que circulava na corte aos domingos, é publicado um instrutivo artigo que aborda a questão do ciúme entre o casal e do modo como a mulher deve proceder diante da traição do marido. Para o autor desse texto, intitulado Conselhos às esposas zelosas, não há nada que mais contribua para a infelicidade conjugal do que o ciúme. Mesmo quando não baseado em simples suspeitas, mas em alguma prova concreta da infidelidade do marido, o artigo aconselha que a esposa aja com paciência e resignação.

\begin{abstract}
As censuras e as violências não são os meios mais próprios para obrigar o marido a emendar-se (...). A impetuosidade das esposas só serve para tornar os maridos piores do que eram e nesse caso vão dar-lhes um pretexto para que eles justifiquem sua má conduta. Em todo caso deve a esposa zelosa proceder de maneira que, perdendo o coração do esposo, não perca nem a sua estima nem o seu respeito. ${ }^{14}$
\end{abstract}

Somente uma esposa amável, dedicada e, se necessário, resignada, poderia tornar-se uma mãe exemplar. Por isso, além de auxiliar a mulher no bom exercício de seu papel de esposa, esses textos publicados na imprensa feminina, assim como as obras de cunho moral dedicadas à educação da mulher, também pretendiam orientá-la em relação à função de mãe. Pela criação dos filhos é que a influência da mulher na sociedade poderia se confirmar de maneira benéfica ou não. Essa missão, aliás, constituía o objetivo mais elevado da família, pois, segundo a perspectiva dos escritores da época, as mães deveriam educar seus filhos e torná-los cidadãos úteis à sociedade e ao Estado: "A mulher que educa seus filhos com as noções do dever, com as lições e com a prática da virtude e com a enobrecedora luz do direito, é benemérita da pátria, porque prepara cidadãos prestantes e dedicados." ${ }^{\prime 15}$

13 A FAMÍLIA: jornal literário dedicado à educação da mãe de família. São Paulo. 13/02/ 1890.

14 O ÁLBUM SEMANAL: cronológico, literário, crítico e de modas. 18/04/1852.

15 MACEDO, Joaquim Manoel de. Mulheres Célebres. Rio de Janeiro: B. L. Garnier, livreiro editor, 1878. p. 46.

Divers@ Revista Eletrônica Interdisciplinar/Matinhos/Vol.5, n.1/p.1-92|/jan./jun.2012 
Cabia à mulher oferecer algumas condições para que se desenvolvessem as qualidades morais e afetivas de seus filhos, já que a "boa mãe era considerada a única capaz de conter o gênio e a semente do mal”.

Eduquemos nossos filhos não só para sua própria felicidade, mas também para que eles concorram mais tarde para o bem geral. É quando, ainda pequena, que a criança deve aprender, sobre o joelho de sua mãe, os doces preceitos que guiarão a sua conduta na vida, sempre cheia de embaraços. A ternura unida à firmeza e a bondade ao exemplo é que formam os bons filhos, os bons esposos e os cidadãos úteis. Ensinemos sobretudo às crianças o respeito para tudo que é bem; façamos com que seu espírito se compenetre dessas verdades que devemos respeitar: a autoridade divina e a autoridade civil. ${ }^{16}$

Para finalizar essa análise, que abordou algumas ideias acerca do casamento divulgadas na imprensa periódica oitocentista destinada ao público feminino, gostaríamos de mencionar alguns artigos que se referem às "solteironas". Essa é uma condição vista como inconcebível, que as moças deveriam evitar a qualquer custo. O cherubim, de 14 de julho de 1887, expressa a seguinte opinião acerca do estado de solteirice nas mulheres:

Mais do que o tempo, as rugas, os cabelos brancos, temem as moças aquele estado
horrível, aquele inferno dantesco - o estado de solteirona. É, de certo, medonho esse
estado em que a mulher vê desfazerem-se todas as ilusões e ser condenada ao
esquecimento de todos que a adoraram, rendiam-lhe homenagem e faziam-se seus
escravos. Algumas dão para críticas e descobrem defeitos e loucuras em todas as
moças, frivolidades em todos os divertimentos; outras dão para criar os sobrinhos, a
quem se entregam de todo o coração; não poucas dão para rezar, como que querendo
reparar as frivolidades passadas; e ainda algumas dão para maldizentes, invejosas,
sarcásticas e verdadeiras víboras. Tal é a condição da solteirona, do que Deus livre
nossas gentis leitoras.

Anais de uma solteirona é o título de um texto publicado em $A$ violeta fluminense ${ }^{18}$, de 17 de janeiro de 1858. Apresentando a condição de solteirice com o mesmo tom trágico do artigo anterior, esse ensaio mostra, ano a ano, como é existência da mulher que não se casa, começando pelos 15 anos e indo até os 50, quando ela morre sem que ninguém sinta sua morte. Ela, que aos 22 havia rejeitado um partido bastante vantajoso, por não ser exatamente o que se considerava um homem da moda, e que aos 23 namorava todos os rapazes que conhecia, começa, a partir dos 25 , a preocupar-se com o fato de não estar ainda casada. Começa a crer que pode passar sem marido opulento, contanto que se case, e limita-se a

16 A MÃE DE FAMÍLIA: jornal científico, literário e ilustrado. Rio de Janeiro: Tipografia dos Editores Lombaerts e Cia., jun de 1879.

17 O CHERUBIM: dedicado ao belo sexo. Rio de Janeiro: Tipografia Montenegro, 14/08/1887.

18 Folha crítica e literária dedicada ao belo sexo, A violeta fluminense surgiu em 1857 no Rio de Janeiro e seus redatores se identificavam pelos sobrenomes Fortes, Almeida e Oliveira; a maioria dos artigos não possui identificação de autoria.

Divers@Revista Eletrônica Interdisciplinar/Matinhos/ Vol.5,n.1/p.1-92//jan./jun.2012 
desejar uma união modesta, que lhe proporcione o necessário para viver sem privações. Aos 29, já começa a perder as esperanças de casamento e teme ser chamada de solteirona. Dos 30 em diante, entra em período de franca decadência, indispõe-se com a melhor amiga, porque esta se casou, e gosta de consolar-se nas desgraças alheias, falando sempre das amigas que fizeram maus casamentos. Seu mau humor também aumenta consideravelmente. Após os 40 anos, apaixona-se pelo jogo, concentra suas atenções em cães e gatos e chega mesmo a tentar suicídio. Há nesse e nos demais textos analisados um incentivo a realização dos matrimônios e uma preocupação social de realizá-los conforme as leis da Igreja. Esse incentivo relacionase aos propósitos desse grupo de periódicos, sempre dispostos a concorrer para o aperfeiçoamento do país através da colaboração da família.

As discussões acerca do casamento marcaram presença constante no mercado editorial brasileiro oitocentista, por tratar-se de uma instituição intimamente vinculada à ordem e ao progresso social. Para os escritores oitocentistas, a frequência dos matrimônios legítimos era determinante para a estabilidade e a moralização da sociedade brasileira. Por essa razão, procurou-se demonstrar a grande importância dessa instituição e quais as vantagens que ela poderia proporcionar aos indivíduos. Do ponto de vista desses escritos, o casamento poderia ajudar a contornar problemas como a criminalidade, o suicídio e a loucura, já que era considerada própria às pessoas casadas uma vida mais afeita aos prazeres do lar e maior senso de dever.

\section{Referências}

\section{Documentos}

A FAMíLIA: Jornal literário dedicado a educação da mãe de família. São Paulo: Tipografia União, 1889.

A MÃE DE FAMíLIA: Jornal científico, literário e ilustrado. Rio de Janeiro: Tipografia dos Editores Lombaerts e Cia., 1879.

A MENSAGEIRA: Revista literária dedicada à mulher brasileira. 1897. Edição fac-similar. São Paulo: Imprensa Oficial do Estado, 1987.

A VIOLETA FLUMINENSE: folha critica e literária dedicada ao bello sexo. Rio de Janeiro, 1857.

BELO SEXO: Periódico religioso, de instrução e recreio, noticioso e critico moderado. Rio de Janeiro: Tipografia Popular, 1862.

Divers@ Revista Eletrônica Interdisciplinar/Matinhos/Vol.5, n.1/p.1-92|/jan./jun.2012 
MARMOTA NA CORTE: Jornal de modas e variedades. Rio de Janeiro: Tipografia Dois de Dezembro, 1849.

O ÁLBUM SEMANAL: Cronológico, literário, critico e de modas. Rio de Janeiro: Tipografia do Pereira, 1851.

O CHERUBIM: Dedicado ao belo sexo. Rio de Janeiro: Tipografia Montenegro, 1885.

O JORNAL DAS SENHORAS: Modas, literatura, belas artes, teatros e críticas. Rio de Janeiro: Tipografia Parisiense, 1852.

O SEXO FEMININO: Semanário dedicado aos interesses da mulher. Campanha: Tipografia do Monarquista, 1873.

RECREIO DAS MOÇAS: órgão do bello sexo. Rio de Janeiro: Tipografia Esperança, 1876.

VIOLETA FLUMINENSE: Folha crítica e literária dedicada ao belo sexo. Rio de Janeiro: Tipografia de F. A. de Almeida, 1857.

\section{Estudos}

BUITONI, Dulcília Helena Schroeder. Mulher de papel: a representação da mulher pela imprensa feminina brasileira. São Paulo: Loyola, 1981.

COSTA, Jurandir Freire. Ordem médica e norma familiar. Rio de Janeiro: Graal, 1989.

DEL PRIORI, Mary. História do amor no Brasil. São Paulo: Contexto, 2005.

NAZZARI, Muriel. O desaparecimento do dote: mulheres, famílias e mudança social em São Paulo, 1600-1900. São Paulo: Companhia das Letras, 2001.

VERONA, Elisa Maria. Da feminilidade oitocentista. Dissertação de Mestrado. Programa de pós-graduação em História da Universidade Estadual Paulista, Franca, 2007.

Divers@ Revista Eletrônica Interdisciplinar/Matinhos/Vol.5, n.1/p.1-92|/jan./jun.2012 